\title{
Microwave-Assisted Method for Simultaneous Extraction and Hydrolysis for Determination of Flavonol Glycosides in Ginkgo Foliage Using Brönsted Acidic Ionic-Liquid $\left[\mathrm{HO}_{3} \mathrm{~S}\left(\mathrm{CH}_{2}\right)_{4} \mathrm{mim}\right] \mathrm{HSO}_{4}$ Aqueous Solutions
}

\author{
Huanhuan Yao ${ }^{\dagger}$, Xinxuan Du ${ }^{\dagger}$, Lei Yang *, Wenjie Wang, Fengjian Yang, Chunjian Zhao, \\ Xiangdong Meng, Lin Zhang and Yuangang $\mathrm{Zu}$ *
}

State Engineering Laboratory for Bio-Resource Eco-Utilization, Northeast Forestry University, Harbin 150040, China; E-Mails: avfdvf@163.com (H.Y.); duxinxuan1985@163.com (X.D.); wjwang225@hotmail.com (W.W.); yangfj@nefu.edu.cn (F.Y.); zcjsj@163.com (C.Z.); mxdhrb@gmail.com (X.M.); zhanglin6600@sina.com (L.Z.)

$\dagger$ These authors contributed equally to this work.

* Authors to whom correspondence should be addressed; E-Mails: ylnefu@163.com (L.Y.); zygnefu@163.com (Y.Z.); Tel.: +86-451-8219-1387 (Y.Z.); Fax: +86-451-8210-2082 (Y.Z.).

Received: 23 April 2012; in revised form: 5 July 2012 / Accepted: 6 July 2012 /

Published: 16 July 2012

\begin{abstract}
The Brönsted acidic ionic-liquid $\left[\mathrm{HO}_{3} \mathrm{~S}\left(\mathrm{CH}_{2}\right)_{4} \mathrm{mim}\right] \mathrm{HSO}_{4}$, a novel dual catalyst-solvent, has been successfully applied in simultaneous microwave-assisted extraction and hydrolysis for the determination of flavonol glycosides in Ginkgo foliage. The parameters, namely the $\left[\mathrm{HO}_{3} \mathrm{~S}\left(\mathrm{CH}_{2}\right)_{4} \mathrm{mim}\right] \mathrm{HSO}_{4}$ concentration, microwave-irradiation power, microwave-irradiation time, and solid-liquid ratio, were optimized. The optimum conditions were: an amount of $1.5 \mathrm{M}\left[\mathrm{HO}_{3} \mathrm{~S}\left(\mathrm{CH}_{2}\right)_{4} \mathrm{mim}\right] \mathrm{HSO}_{4}$, a microwave-irradiation power of $120 \mathrm{~W}$, an irradiation time of $15 \mathrm{~min}$, and a solid-liquid ratio of 1:30 $\mathrm{g} / \mathrm{mL}$. Compared with traditional methods the proposed approach demonstrates higher efficiency in a shorter operating time, and is an efficient, rapid, and simple sample preparation method.
\end{abstract}

Keywords: Ginkgo biloba; ionic liquid; $\left[\mathrm{HO}_{3} \mathrm{~S}\left(\mathrm{CH}_{2}\right)_{4} \mathrm{mim}\right] \mathrm{HSO}_{4}$; microwave-assisted extraction; hydrolysis; flavonol glycoside 


\section{Introduction}

Ginkgo foliage has been one of the most popular traditional Chinese medicines for several thousand years [1]. Today, it is one of the top-selling herbs in the United States and Europe. Extracts of Ginkgo biloba (Egb) have been proven to be clinically effective in the treatments of peripheral vascular diseases, Alzheimer's disease, dementia in elderly people, and tinnitus. The extracts have a number of functions. For example, they inhibit platelet aggregation [2], act as antioxidants and radical scavengers, and protect the central nervous system [3,4]. The primary active components are flavonol glycosides (24\%) and a small amount of terpene lactones (6\%) [5]. The flavonoids are primarily quercetin, kaempferol, and isorhamnetin. There are Egb products, including drugs and health foods, on the market in many countries.

There are many papers in the literature on the analysis and extraction techniques for Ginkgo flavonol glycosides. Traditionally, the extraction and hydrolysis of flavonol glycosides were separate procedures. The flavonol glycosides of Ginkgo were isolated by Soxhlet, maceration and heat reflux extractions [6,7] with volatile organic solvents, including methanol, ethanol, acetone and some mixed solvents. In contrast, the hydrolysis of the various Egb glycosides to their three primary aglycones is commonly achieved by refluxing the sample with aqueous/ethanolic hydrochloric acid for approximately $2 \mathrm{~h}$. These conventional extraction techniques are inconvenient, inefficient, time-consuming, energy-consuming, result in degradation of target components, involve large volumes of toxic organic solvents and lead to unsatisfactory recoveries. It is therefore necessary to develop new and effective methods to find alternatives to traditional techniques.

Recently, microwave-assisted extraction has been accepted as a potential and powerful alternative to conventional techniques for the extraction of target components of plant materials. There have been many studies showing that microwave-assisted extraction is more effective than conventional methods for the extraction of flavonol glycosides from medicinal plants [8,9]. The extraction time was reduced, less solvent was used, and increased amounts of flavonol glycosides were extracted. Microwave hydrolysis has already been successfully used in food sample analysis, for example, for the determination of amino acids, choline, and vitamin $\mathrm{B}_{12}[10,11]$.

Ionic liquids are organic salts that exist as liquids below a threshold temperature. They are composed of large organic cations and small inorganic or organic anions [12]. They have recently attracted much research interest for a variety of applications because of their excellent properties: extremely low vapor pressure, high thermal stability, wide liquid range, tunable viscosity, miscibility with water and organic solvents, and good solubility and extractability for various organic compounds; moreover, ionic liquids can efficiently absorb and transfer microwave energy [13,14]. In the past few years, ionic liquids have been used as attractive green alternatives to conventional volatile organic solvents in various applications, including analytical applications [15-17], organic synthesis, catalysis $[13,18,19]$ and separation [20-23]. Ionic liquids have also been widely used as catalysts in many reactions, such as alkylation, esterification, Michael addition, oligomerization and rearrangement. However, there have been few studies of hydrolysis reactions using ionic liquids as catalysts. This might be because one of the limitations of the traditional ionic liquids, namely the very weak acidities [24], makes it hard to obtain good catalytic activities in hydrolysis reactions using ionic liquids as catalysts. Although some studies have investigated the effects of ionic liquids in 
hydrolysis reactions, the ionic liquids, for example 1-butyl-3-methylimidazolium chloride, 1-butyl-3-methylimidazolium bromide $([\mathrm{Bmim}] \mathrm{Br})$, and 1-butyl-3-methylimidazolium tetrafluoroborate, were only used as solvents or additives to enhance enzymatic or acid-catalyzed processes [25,26]. Recently, the introduction of Brönsted acidic functional groups into the cations or anions of ionic liquids, especially $\mathrm{SO}_{3} \mathrm{H}$ functional groups, which obviously enhance their acidities [27-29], has shown great promise for the use of ionic liquids as green catalysts with good catalytic activities in hydrolysis reactions. $\left[\mathrm{HO}_{3} \mathrm{~S}\left(\mathrm{CH}_{2}\right)_{4}\right.$ mim] $\mathrm{HSO}_{4}$ is a Brönsted acidic ionic liquid that can be used to extract flavonol glycosides and to catalyze their hydrolysis.

In the present study, the potential of the Brönsted acidic ionic liquid $\left[\mathrm{HO}_{3} \mathrm{~S}\left(\mathrm{CH}_{2}\right)_{4} \mathrm{mim}\right] \mathrm{HSO}_{4}$ as a dual catalyst-solvent in the microwave-assisted simultaneous extraction and hydrolysis of flavonol glycosides from G. biloba was investigated. Various parameters influencing the procedure were optimized systematically. The ionic-liquid-based microwave-assisted simultaneous extraction and hydrolysis (ILMASEH) approach developed here was compared with conventional approaches. The simultaneous extraction and hydrolysis of flavonol glycosides demonstrated that the proposed ILMASEH approach showed great potential for easy quality assessment of G. biloba as well as of other flavonoid-rich plants.

\section{Results and Discussion}

\subsection{Effect of Solvent Concentration}

The optimum $\left[\mathrm{HO}_{3} \mathrm{~S}\left(\mathrm{CH}_{2}\right)_{4} \mathrm{mim}\right] \mathrm{HSO}_{4}$ concentration in aqueous solution for ILMASEH was determined by carrying out extractions and hydrolyses with $\left[\mathrm{HO}_{3} \mathrm{~S}\left(\mathrm{CH}_{2}\right)_{4} \mathrm{mim}\right] \mathrm{HSO}_{4}$ solutions of different concentrations (from 0.25 to $2.5 \mathrm{M}$ ). In the experiments, $1.0 \mathrm{~g}$ of sample was soaked in $30 \mathrm{~mL}$ of $\left[\mathrm{HO}_{3} \mathrm{~S}\left(\mathrm{CH}_{2}\right)_{4} \mathrm{mim}\right] \mathrm{HSO}_{4}$ and then extracted under a microwave-irradiation power of $120 \mathrm{~W}$ and an irradiation time of $15 \mathrm{~min}$. The results in Figure la show that the yield increased in the $\left[\mathrm{HO}_{3} \mathrm{~S}\left(\mathrm{CH}_{2}\right)_{4} \mathrm{mim}\right] \mathrm{HSO}_{4}$ concentration range 0.25-1.5 M. Upon further increases, however, a slight decrease in the yield was observed. The $1.5 \mathrm{M}\left[\mathrm{HO}_{3} \mathrm{~S}\left(\mathrm{CH}_{2}\right)_{4} \mathrm{mim}\right] \mathrm{HSO}_{4}$ solution was therefore selected as the optimum ionic-liquid concentration. We speculate that the degradation or isomerization of aglycones often increases at high ionic liquid concentrations, which could lead to a decrease in the calculated yield of glycosides.

\subsection{Effect of Microwave-Irradiation Power}

Optimization of the microwave power used during ILMASEH is very important for ensuring efficient extraction and hydrolysis, and the effect of this variable was examined. In the experiments,

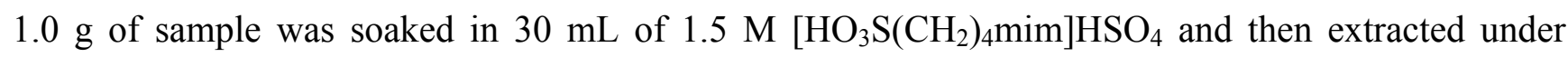
irradiation for $15 \mathrm{~min}$. The yields obtained at different powers (120, 230, 385, 540 and $700 \mathrm{~W}$ ) gradually decreased as the microwave power increased from 120 to $700 \mathrm{~W}$. The ILMASEH time was maintained constant at 10 min throughout the experiments. It was found that as the microwave power increased, the yields decreased consistently (Figure 1b). This indicated that high-power microwave irradiation might result in carbonization of the raw materials as a result of internal overheating, isomerization of flavonol aglycones, and energy consumption. This phenomenon was also observed for 
ionic-liquid microwave-assisted extraction of lignans by Ma et al. [17]. The minimum microwave power tested $(120 \mathrm{~W})$ was therefore the optimum power for maximum yield.

Figure 1. Effects of $\left[\mathrm{HO}_{3} \mathrm{~S}\left(\mathrm{CH}_{2}\right)_{4} \mathrm{mim}\right] \mathrm{HSO}_{4}$ concentration: (a) microwave power, (b) microwave time, (c) solid-liquid ratio and (d) ionic-liquid-based microwave-assisted simultaneous extraction and hydrolysis (ILMASEH) process was performed in a microwave unit with a power of $700 \mathrm{~W}$. Dried sample was mixed with $\left[\mathrm{HO}_{3} \mathrm{~S}\left(\mathrm{CH}_{2}\right)_{4} \mathrm{mim}\right] \mathrm{HSO}_{4}$ in water at different concentrations and then irradiated with microwaves for specified times.
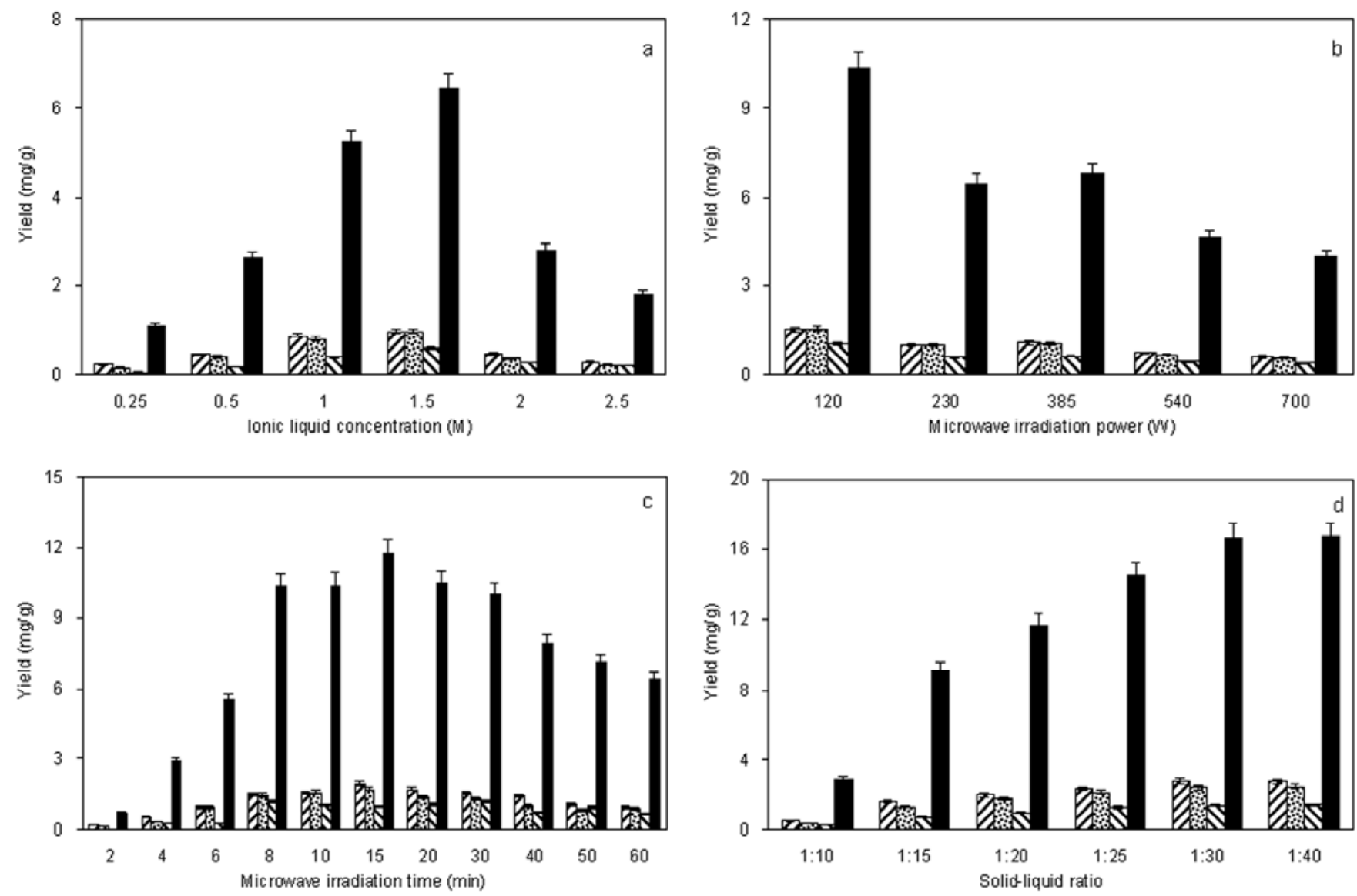

Quercetin $\mathbf{0}$ Kaempferol $\Delta$ Isorhamnetin - Total flavonol glycosides

\subsection{Effect of Microwave-Irradiation Time}

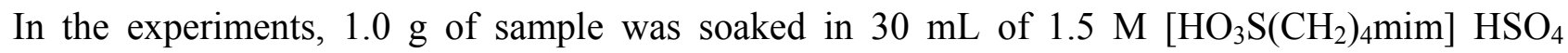
and then extracted under a microwave-irradiation power of $120 \mathrm{~W}$. The influence of the microwave-irradiation time on the yields of flavonol aglycones was examined over the range of 2-60 min, and the results are shown in Figure 1c. The results show that when the irradiation time was increased from 2 to $15 \mathrm{~min}$, the yields of the three flavonol aglycones increased significantly. The yields of the three flavonol aglycones were low during the first 15 min indicating that more time was needed for microwave irradiation to disrupt the cell walls, aid the release of the flavonol glycosides into the solvent, and effectively hydrolyze the flavonol glycosides. On prolonged application of microwave irradiation, for more than $15 \mathrm{~min}$, the yields of the three flavonol aglycones from Ginkgo foliage decreased, which indicated that the higher temperature probably caused degradation or 
isomerization of the flavonol aglycones; similar results were obtained in the extraction of alkaloids from Camptotheca acuminate [23] and of saponins from Ganoderma atrum [30]. The application of microwaves for $15 \mathrm{~min}$ was therefore selected for all subsequent experiments.

\subsection{Effect of Solid-Liquid Ratio}

The solid-liquid ratio is a crucial factor and was also studied to optimize the yields. Large solvent volumes could make the procedure difficult and lead to unnecessary waste, but small volumes may lead to incomplete extraction and hydrolysis. A series of experiments was carried out with different

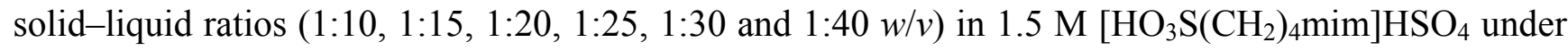
a microwave-irradiation power of $120 \mathrm{~W}$ and an irradiation time of $15 \mathrm{~min}$ to evaluate the effect of the solid-liquid ratio. Figure 1d shows that the yields of the three flavonol aglycones increased with increasing solvent volume for solid-liquid ratios up to 1:30. Higher solvent volumes, however, did not significantly improve the yields of the flavonol aglycones. A solid-liquid ratio of 1:30 was therefore chosen as the optimum solid-liquid ratio.

Based on the above experiments, the optimum ILMASEH conditions were found to be as follows:

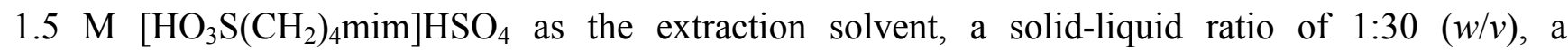
microwave power of $120 \mathrm{~W}$, and an irradiation time of $15 \mathrm{~min}$.

\subsection{Comparison of ILMASEH Approach with Conventional Methods}

In the present study, pharmacopoeia of the People's Republic of China sample preparation method (PPRCM), European pharmacopoeia sample preparation method (EPM), United States pharmacopeia and national formulary sample preparation method (USP-NFM), acidic ethanol microwave-assisted sample preparation method (AEMM), 1-butyl-3-methylimidazolium bromide ([Bmim]Br) microwave-assisted sample preparation method (BMM) and acidic [Bmim]Br microwave-assisted sample preparation method (ABMM) techniques were compared with respect to their yields of total flavonol glycosides from Ginkgo foliage. The total flavonol glycosides yields obtained using these six methods are summarized in Table 1. The total flavonol glycosides yields obtained using ILMASEH and ABMM were higher than those obtained using AEMM, PPRCM, EPM, and USP-NFM. In ILMASEH and ABMM, the flavonol glycosides in Ginkgo foliage could absorb sufficient microwave energy to be quickly transferred into the extraction solvent and hydrolyzed; the extraction time was significantly reduced and the yields increased considerably. This showed that compared with traditional methods, ILMASEH used only a small amount of ionic liquid and could obtain higher yields in shorter extraction times (15 min compared with $6.50 \mathrm{~h}$ for PPRCM, $2.75 \mathrm{~h}$ for EPM, and $2.25 \mathrm{~h}$ for USP-NFM), indicating that the $\left[\mathrm{HO}_{3} \mathrm{~S}\left(\mathrm{CH}_{2}\right)_{4} \mathrm{mim}\right] \mathrm{HSO}_{4}$ ionic-liquid was a dual catalyst-solvent and that ILMASEH was a more rapid and efficient method. 
Table 1. Comparison of ILMASEH approach with reference and conventional methods.

\begin{tabular}{|c|c|c|c|c|c|c|c|c|c|}
\hline \multirow[b]{2}{*}{ Methods } & \multirow[b]{2}{*}{ Solvents } & \multirow{2}{*}{$\begin{array}{c}\text { Solvent } \\
\text { volume }(\mathrm{mL} / \mathrm{g})\end{array}$} & \multirow{2}{*}{$\begin{array}{l}\text { Extraction } \\
\text { method }\end{array}$} & \multirow{2}{*}{$\begin{array}{c}\text { Power } \\
(\mathbf{W})\end{array}$} & \multirow{2}{*}{$\begin{array}{l}\text { Heating } \\
\text { time (h) }\end{array}$} & \multicolumn{4}{|c|}{ Yield (mg/g) } \\
\hline & & & & & & Quercetin & Kaempferol & Isorhamnetin & $\begin{array}{c}\text { Total flavonol } \\
\text { glycosides } \\
\end{array}$ \\
\hline ILMASEH & $1.5 \mathrm{M}\left[\mathrm{HO}_{3} \mathrm{~S}\left(\mathrm{CH}_{2}\right)_{4} \mathrm{mim}\right] \mathrm{HSO}_{4}$ & 35 & Microwave & 120 & 0.25 & $2.75 \pm 0.13$ & $2.36 \pm 0.11$ & $1.37 \pm 0.06$ & $16.33 \pm 0.76$ \\
\hline PPRCM & $\begin{array}{c}\text { Chloroform/Methanol/ } \\
\text { Hydrochloric acid }\end{array}$ & 225 & Soxhlet & 500 & 6.50 & $2.45 \pm 0.12$ & $1.90 \pm 0.08$ & $1.19 \pm 0.06$ & $13.94 \pm 0.65$ \\
\hline EPM & $\begin{array}{c}\text { Acetone- } \mathrm{H}_{2} \mathrm{O}(60: 40) \\
\text { Hydrochloric acid }\end{array}$ & Approx. 60 & Reflux & 500 & 2.75 & $2.35 \pm 0.14$ & $1.95 \pm 0.11$ & $1.23 \pm 0.07$ & $13.93 \pm 0.81$ \\
\hline USP-NFM & Ethanol- $\mathrm{H}_{2} \mathrm{O}-\mathrm{Hydrochloric}$ acid $(50: 20: 8)$ & 78 & Reflux & 500 & 2.25 & $2.44 \pm 0.11$ & $2.19 \pm 0.12$ & $1.35 \pm 0.07$ & $15.07 \pm 0.76$ \\
\hline AEMM & Ethanol- $\mathrm{H}_{2} \mathrm{O}-\mathrm{Hydrochloric}$ acid $(50: 20: 8)$ & 78 & Microwave & 120 & 0.25 & $2.56 \pm 0.12$ & $2.15 \pm 0.10$ & $1.20 \pm 0.06$ & $14.83 \pm 0.71$ \\
\hline BMM & $1.5 \mathrm{M}[\mathrm{Bmim}] \mathrm{Br}$ & 78 & Microwave & 120 & 0.25 & $0.57 \pm 0.02$ & $0.69 \pm 0.03$ & $0.30 \pm 0.01$ & $3.92 \pm 0.15$ \\
\hline ABMM & $\begin{array}{c}1.5 \mathrm{M}[\mathrm{Bmim}] \mathrm{Br} \\
(\mathrm{pH} 0.5, \text { adjusted with } \mathrm{HCl})\end{array}$ & 78 & Microwave & 120 & 0.25 & $2.71 \pm 0.14$ & $2.45 \pm 0.11$ & $1.35 \pm 0.06$ & $16.34 \pm 0.78$ \\
\hline
\end{tabular}




\subsection{Method Validation}

The stabilities of the aglycones under the experimentally derived optimum conditions were assessed by subjecting standards of quercetin, kaempferol, and isorhamnetin to microwave irradiation for $15 \mathrm{~min}$ at a microwave power of $120 \mathrm{~W}$. The recoveries of the aglycones were assumed to be indicative of the stability of the aglycones under the ILMASEH conditions used (Table 2). The average complete recovery under the ILMASEH operating conditions varied from $98.0 \%$ to $99.3 \%$ with no changes in retention times observed for the aglycones. Degradation is therefore insignificant under the selected optimum conditions. For the standards in $1.5 \mathrm{M}\left[\mathrm{HO}_{3} \mathrm{~S}\left(\mathrm{CH}_{2}\right)_{4} \mathrm{mim}\right] \mathrm{HSO}_{4}$ solution stored for 7 days, the average recoveries of quercetin, kaempferol and isorhamnetin were $97.0 \%, 92.7 \%$ and $91.0 \%$, respectively.

Table 2. Stability studies of quercetin, kaempferol, and isorhamnetin standards under optimum ILMASEH conditions. ILMASEH conditions: microwave power $120 \mathrm{~W}$, microwave time $15 \mathrm{~min}$, 1:30 solid-liquid ratio, prepared with $1.5 \mathrm{M}\left[\mathrm{HO}_{3} \mathrm{~S}\left(\mathrm{CH}_{2}\right)_{4} \mathrm{mim}\right] \mathrm{HSO}_{4}$.

\begin{tabular}{|c|c|c|c|c|c|c|c|}
\hline Compounds & $\begin{array}{c}\text { Initial } \\
\text { concentration } \\
\left(\mathbf{m g ~ m L} \mathbf{~ L}^{-1}\right)\end{array}$ & $\begin{array}{c}\text { Recovered } \\
\text { concentration } \\
\text { after ILMASEH } \\
\left(\mathbf{m g ~ m L} \mathbf{~ L}^{-1}\right) \\
\end{array}$ & $\begin{array}{l}\text { RSD\% } \\
(n=3)\end{array}$ & $\begin{array}{c}\text { Average } \\
\text { recovery } \\
(\%)\end{array}$ & $\begin{array}{c}\text { Recovered } \\
\text { concentration } \\
\text { after } 7 \text { day } \\
\left(\mathrm{mg} \mathrm{mL}^{-1}\right) \\
\end{array}$ & $\begin{array}{l}\text { RSD\% } \\
(n=3)\end{array}$ & $\begin{array}{c}\text { Average } \\
\text { recovery } \\
(\%)\end{array}$ \\
\hline Quercetin & 2.00 & 1.97 & 0.96 & 98.5 & 1.94 & 0.97 & 97.0 \\
\hline Kaempferol & 1.50 & 1.48 & 0.97 & 99.3 & 1.39 & 0.99 & 92.7 \\
\hline Isorhamnetin & 1.00 & 0.98 & 1.01 & 98.0 & 0.91 & 1.03 & 91.0 \\
\hline
\end{tabular}

Under the optimized conditions detailed above, three samples of Ginkgo foliage, which had been spiked with quercetin, kaempferol and isorhamnetin were extracted and the recoveries were analyzed; the results are shown in Table 3. The recoveries of quercetin, kaempferol, and isorhamnetin from Ginkgo foliage were $99.49 \%, 99.75 \%$ and $100.29 \%$, respectively.

Table 3. Recovery of quercetin, kaempferol and isorhamnetin from Ginkgo foliage $(n=3)$.

\begin{tabular}{|c|c|c|c|c|c|c|c|c|c|c|c|c|}
\hline \multirow[b]{2}{*}{ Sample } & \multicolumn{3}{|c|}{$\begin{array}{l}\text { Aglycone content of } \\
\text { the sample (mg) }\end{array}$} & \multicolumn{3}{|c|}{$\begin{array}{c}\text { Amount of added } \\
\text { aglycone standard (mg) }\end{array}$} & \multicolumn{3}{|c|}{$\begin{array}{l}\text { Amount of the sample } \\
\text { determined with added } \\
\text { aglycone standard (mg) }\end{array}$} & \multicolumn{3}{|c|}{ Recovery (\%) } \\
\hline & 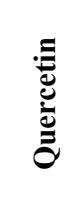 & 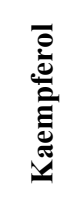 & 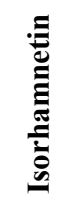 & 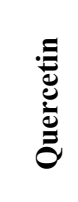 & 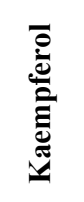 & 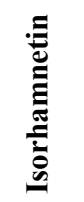 & 总 & 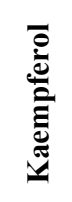 & 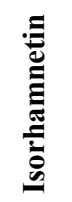 & 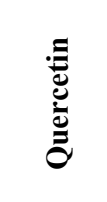 & 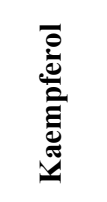 & 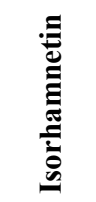 \\
\hline 1 & 2.80 & 2.46 & 1.39 & 1.40 & 1.30 & 0.50 & 4.23 & 3.72 & 1.91 & 100.71 & 98.94 & 101.06 \\
\hline 2 & 2.80 & 2.46 & 1.39 & 2.80 & 2.60 & 1.00 & 5.57 & 5.1 & 2.41 & 99.46 & 100.79 & 100.84 \\
\hline 3 & 2.80 & 2.46 & 1.39 & 4.20 & 3.90 & 1.50 & 6.88 & 6.33 & 2.86 & 98.29 & 99.53 & 98.96 \\
\hline Average & & & & & & & & & & 99.49 & 99.75 & 100.29 \\
\hline
\end{tabular}

To determine the repeatability of the novel method, five samples of the same weight $(0.5 \mathrm{~g})$ were processed under the optimum conditions. The mean yields of quercetin, kaempferol and isorhamnetin obtained under the optimized conditions showed good repeatability with calculated RSD values of 
$3.3 \%, 4.2 \%$ and $3.9 \%$, respectively. This shows that the proposed ILMASEH method has an acceptable level of repeatability.

The results suggested that quercetin, kaempferol and isorhamnetin were stable in the ionic-liquid solutions and in the extracts. These method validation studies indicate that the proposed method is credible.

\section{Experimental Section}

\subsection{Materials and Chemicals}

Ginkgo foliage was purchased from the Tancheng Medicinal Materials Market (Shandong, China). The dried samples were powdered to a homogeneous size and then sieved (60-80 mesh) prior to use. Quercetin, kaempferol, and isorhamnetin standards were purchased from the National Institute for the Control of Pharmaceutical and Biological Products (Beijing, China). HPLC-grade methanol (J\&K Chemical Ltd. Beijing, China) and ultrapure water prepared using a Milli-Q purification system (Millipore, Bedford, MA, USA) were used as the HPLC mobile phase. Ionic liquids, $\left[\mathrm{HO}_{3} \mathrm{~S}\left(\mathrm{CH}_{2}\right)_{4} \mathrm{mim}\right] \mathrm{HSO}_{4}$ and $[\mathrm{Bmim}] \mathrm{Br}$, were obtained from Chengjie Co., Ltd. (Shanghai, China) and used without further purification. Some physicochemical properties of the ionic liquids studied are listed in Table 4. All other chemicals used in this study were of at least analytical grade and were obtained from Sinopharm Chemical Reagent Co., Ltd (Shanghai, China). All solutions and samples prepared for chromatographic analysis were filtered through a $0.45-\mu \mathrm{m}$ microporous membrane (Guangfu, Tianjin, China) before being injected onto the HPLC column.

Table 4. Physicochemical properties of the ionic liquids studied.

\begin{tabular}{ccccc}
\hline Ionic liquid & Anion & $\begin{array}{c}\text { Form } \\
\left(25^{\circ} \mathbf{C}\right)\end{array}$ & $\begin{array}{c}\text { Solubility in } \mathbf{H}_{\mathbf{2}} \mathbf{O} \\
\mathbf{( g / 1 0 0} \mathbf{~ m L})\end{array}$ \\
\hline$\left[\mathrm{HO}_{3} \mathrm{~S}_{\left.\left(\mathrm{CH}_{2}\right)_{4} \mathrm{mim}\right]}\right.$ & $\mathrm{SO}_{3} \mathrm{H}$ & $\mathrm{HSO}_{4}^{-}$ & Liquid & Totally miscible \\
\hline $\mathrm{Bmim}] \mathrm{Br}$ & $\mathrm{Br}_{4}^{-}$ & Solid & Totally miscible \\
\hline
\end{tabular}

\subsection{HPLC Analysis and Quantification}

The HPLC system consisted of a Waters 717 autosampler, a 1525 binary pump, a 717 automatic column temperature control compartment and a 2487 UV-detector (Waters, Milford, MA, USA). Chromatographic separation was performed on a Kromasil 100-5 $\mathrm{C}_{18}$ reversed-phase column (4.6 mm $\times 250 \mathrm{~mm}, 5 \mu \mathrm{m}$, AkzoNobel, Bohus, Sweden).

Stock solutions of quercetin, kaempferol, and isorhamnetin were prepared in methanol at a concentration of $30 \mu \mathrm{g} / \mathrm{mL}$. Working standard solutions were prepared by serial dilution of the stock solutions in methanol and then stored at $1-4{ }^{\circ} \mathrm{C}$ in darkness until the HPLC analysis.

The extracts were directly injected into the liquid chromatograph. The mobile phase was composed of methanol: $1 \%$ aqueous acetic acid solution $(52.5: 47.5, v / v)$. The flow rate was $1 \mathrm{~mL} / \mathrm{min}$ and the injection volume was $10 \mu \mathrm{L}$. The column temperature was maintained at $25^{\circ} \mathrm{C}$. The $\mathrm{UV}$ detection 
wavelength was $360 \mathrm{~nm}$, where quercetin, kaempferol, and isorhamnetin have optimum absorbances. Under these conditions, the quercetin, kaempferol and isorhamnetin were separated sufficiently (Figure 2). Quercetin, kaempferol, and isorhamnetin were identified by comparing their retention times with the corresponding peaks in the standard solutions.

The corresponding calibration curves for each compound are $Y_{\text {quercetin }}=258971 x-34818(r=0.9991)$, $Y_{\text {kaempferol }}=254792 x+8635.7(r=0.9993)$, and $Y_{\text {isorhamnetin }}=100039 x+34462(r=0.9995)$. Good linearities were found for quercetin, kaempferol, and isorhamnetin in the range of $2.5-30 \mu \mathrm{g} / \mathrm{mL}$.

\subsection{Ionic Liquid-based Microwave-Assisted Simultaneous Extraction and Hydrolysis (ILMASEH)}

The experimental setup is shown schematically in Figure 3. A household microwave oven (Glanz, Shunde, China) was used for ILMASEH with at a microwave irradiation frequency of $2450 \mathrm{MHz}$. The maximum output power of the oven was $700 \mathrm{~W}$. In order to examine the effect of the microwave power, five power levels, 100\% $(700 \mathrm{~W}), 77 \%(540 \mathrm{~W}), 55 \%(385 \mathrm{~W}), 33 \%(230 \mathrm{~W})$, and 17\% $(120 \mathrm{~W})$ were studied. The whole system was run at atmospheric pressure.

The dimensions of the interior cavity of the oven were $215 \times 350 \times 330 \mathrm{~mm}^{3}$. The microwave oven was modified by drilling a hole in the top. A round-bottomed flask of a capacity of $50 \mathrm{~mL}$ was placed in the oven and connected to a reflux condenser through the hole. After placing the reflux condenser in the oven, the hole around the neck of the flask was covered with polytetrafluoroethylene (PTFE) to prevent microwave leakage.

Figure 2. Comparative HPLC chromatograms for quercetin, kaempferol, and isorhamnetin

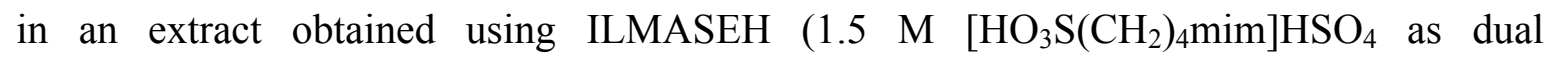
catalyst-solvent) (a) and using EPM method (b). Inset: chemical structures of three predominant flavonol aglycones in Ginkgo biloba.
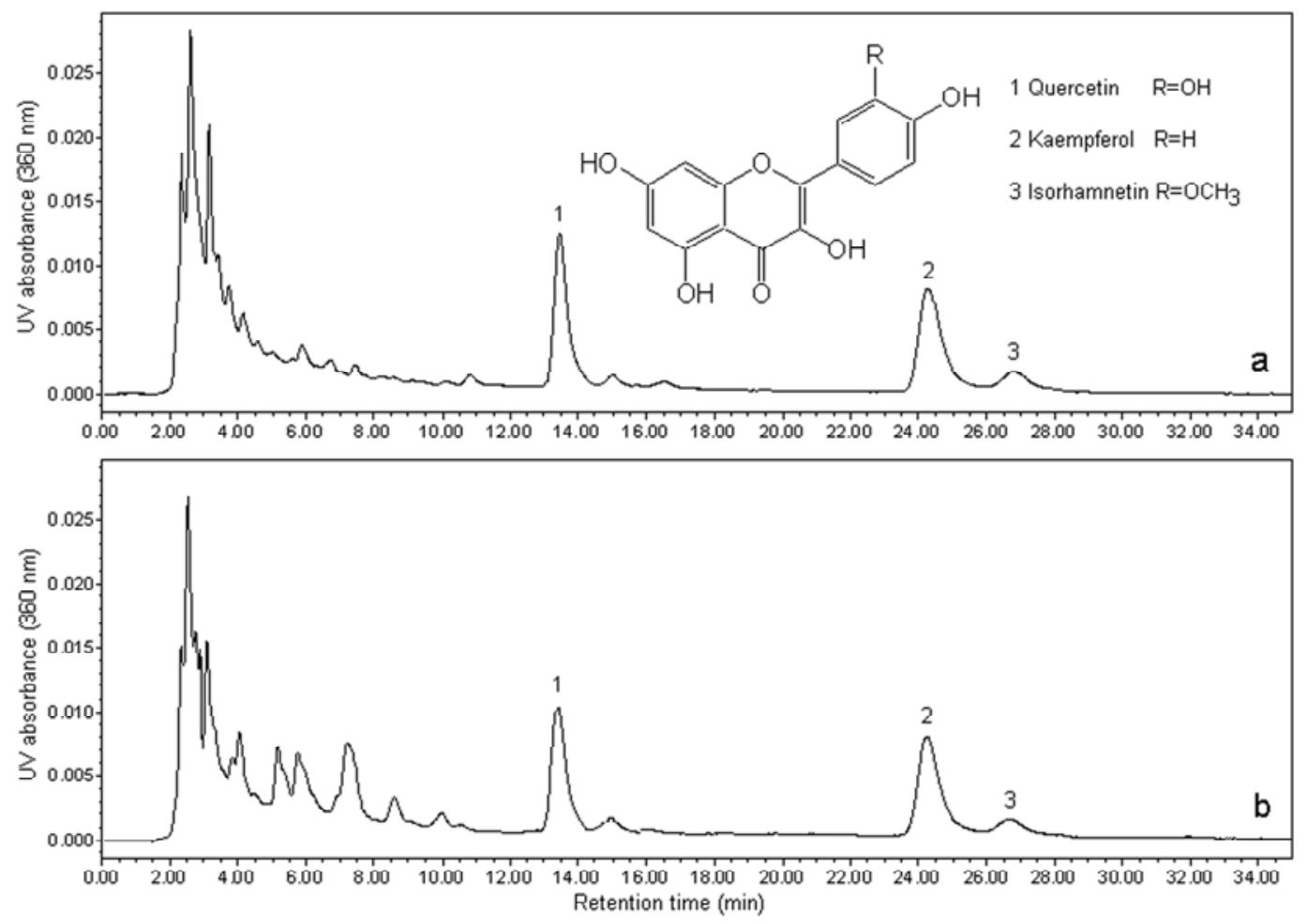
Figure 3. Schematic diagram of ionic liquids based microwave-assisted simultaneous extraction and hydrolysis apparatus.

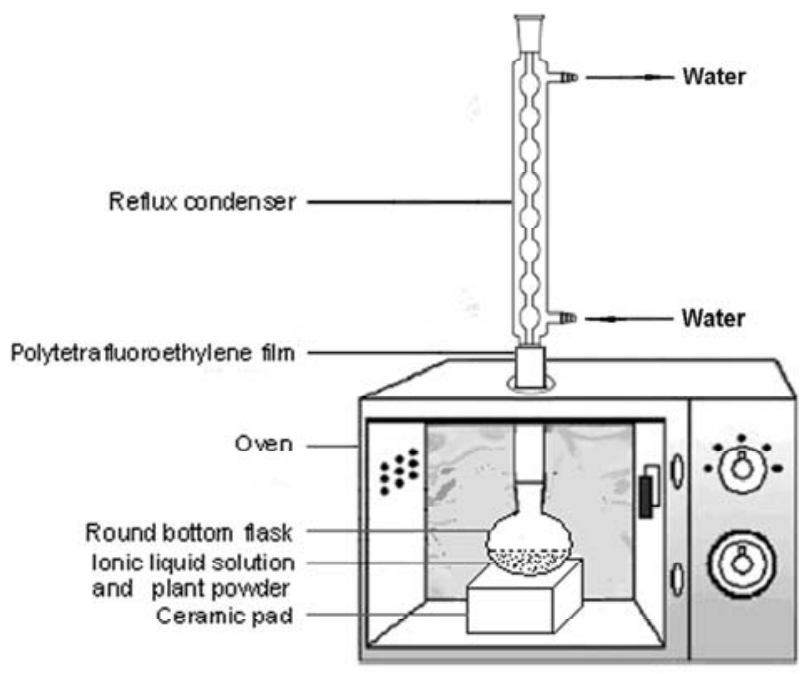

A dried sample $(0.5 \mathrm{~g})$ was mixed with $15 \mathrm{~mL}$ of ionic-liquid solution in a $50 \mathrm{~mL}$ flask and then the suspension was irradiated with microwaves. The optimum concentration of the selected ionic liquid, microwave power, irradiation time, and solid-liquid ratio was systematically studied in this work. The extracts obtained were rapidly cooled to room temperature using a cold bath and filtered through a 0.45- $\mu \mathrm{m}$ PTFE microporous membrane (Guangfu, Tianjin, China) for subsequent HPLC analysis.

The flavonol glycoside concentrations were determined from the peak areas of quercetin, kaempferol and isorhamnetin using the following equation:

$$
\text { Individual glycoside }(\mathrm{mg} / \mathrm{g})=\left(C \times F_{V} \times F\right) /(W \times 1000)
$$

where $C$ is the aglycone concentration determined from the standard curve, $F_{V}$ is the final volume $(\mathrm{mL})$, $F$ is a conversion factor (2.504 for quercetin, 2.588 for kaempferol, and 2.437 for isorhamnetin) [31], and $W$ is the sample weight $(\mathrm{g})$. So,

Total flavonol glycosides $(\mathrm{mg} / \mathrm{g})=$ quercetin glycosides $(\mathrm{mg} / \mathrm{g})+$ kaempferol glycosides $(\mathrm{mg} / \mathrm{g})+$ isorhamnetin glycosides $(\mathrm{mg} / \mathrm{g})$

\subsection{Pharmacopoeia of the People's Republic of China Sample Preparation Method (PPRCM)}

Powdered Ginkgo foliage was weighed (1.0 g) and transferred to a Soxhlet extractor. Chloroform $(100 \mathrm{~mL})$ was added and the mixture was heated under reflux for $2 \mathrm{~h}$. The chloroform solution was discarded, $100 \mathrm{~mL}$ of methanol was added, and the mixture was heated under reflux for $4 \mathrm{~h}$. The liquid extract was decanted and concentrated under a vacuum to dryness. A methanol/25\% $\mathrm{HCl}$ (4:1) solution $(25 \mathrm{~mL})$ was added and the mixture was refluxed for $0.5 \mathrm{~h}$ [32]. An aliquot of the sample was filtered (PTFE, $0.45 \mu \mathrm{m}$, Guangfu, Tianjin China) prior to HPLC analysis.

\subsection{European Pharmacopoeia Sample Preparation Method (EPM)}

Powdered Ginkgo foliage was weighed $(2.5 \mathrm{~g})$ and transferred to a $250 \mathrm{~mL}$ boiling flask. Acetone solution $(60 \% v / v, 50 \mathrm{~mL})$ was added and the mixture was heated under reflux for $70 \mathrm{~min}$. The liquid 
extract was decanted and filtered, and $40 \mathrm{~mL}$ of $60 \% \mathrm{v} / \mathrm{v}$ acetone solution were added to the remaining solid. The mixture was heated under reflux for an additional $70 \mathrm{~min}$. The sample was cooled and filtered into a $100 \mathrm{~mL}$ volumetric flask containing the initial extract. The final extract $(50 \mathrm{~mL})$ was transferred to a $250 \mathrm{~mL}$ round-bottomed flask. The contents were evaporated under a vacuum until the steady flow of condensed solvent ceased. The contents were transferred to a 50 -mL volumetric flask, $4.4 \mathrm{~mL}$ of hydrochloric acid were added, and the sample was diluted to volume with methanol. The flask contents were centrifuged for approximately $5 \mathrm{~min}$. Aliquots $(10 \mathrm{~mL})$ of supernatant were transferred to $10-\mathrm{mL}$ glass vials and the vials were sealed with aluminum caps. The vials were submerged in a boiling-water bath for $25 \mathrm{~min}$ [33]. An aliquot of the sample was filtered (PTFE, $0.45 \mu \mathrm{m}$, Guangfu, Tianjin, China) prior to HPLC analysis.

\subsection{United States Pharmacopeia and National Formulary Sample Preparation Method (USP-NFM)}

Powdered Ginkgo foliage was weighed $(1.0 \mathrm{~g})$ and transferred to a $250 \mathrm{~mL}$ boiling flask. Ethanol $(50 \mathrm{~mL})$, water $(20 \mathrm{~mL})$, and hydrochloric acid $(8 \mathrm{~mL})$ were added and the mixture was refluxed for approximately $135 \mathrm{~min}$. The sample was cooled to room temperature and filtered into a $100 \mathrm{~mL}$ volumetric flask. The sample was diluted to volume with water and mixed well by inversion [34]. An aliquot of the sample was filtered (PTFE, $0.45 \mu \mathrm{m}$, Guangfu, Tianjin, China) prior to HPLC analysis.

\subsection{Other Reference Sample Preparation Methods}

Acidic ethanol microwave-assisted sample preparation method (AEMM): Powdered Ginkgo foliage was weighed $(1.0 \mathrm{~g})$ and transferred to a $250 \mathrm{~mL}$ boiling flask. Ethanol $(50 \mathrm{~mL})$, water $(20 \mathrm{~mL})$, and hydrochloric acid $(8 \mathrm{~mL})$ were added, and the mixture was subjected to microwave irradiation for $15 \mathrm{~min}$ at $120 \mathrm{~W}$. The subsequent steps were the same as those in USP-NFM.

[Bmim] $\mathrm{Br}$ microwave-assisted sample preparation method (BMM): [Bmim] $\mathrm{Br}$ was used as the solvent in the sample preparation. The experiments were operated under the optimum conditions, except for the solvent type. The subsequent steps were the same as those in ILMASEH.

Acidic [Bmim] Br microwave-assisted sample preparation method (ABMM): A $1.5 \mathrm{M}$ [Bmim] $\mathrm{Br}$ acidic solution ( $\mathrm{pH} 0.5$, adjusted with $6.0 \mathrm{~mol} / \mathrm{L}$ of hydrochloric acid) was used as the solvent in the sample preparation. The experiments were operated under the optimum conditions, except for the solvent type. The subsequent steps were the same as those in ILMASEH.

\section{Conclusions}

The application of ILMASEH was successfully developed for simultaneous extraction and hydrolysis for the determination of flavonol glycosides in Ginkgo foliage. The ILMASEH conditions, namely the $\left[\mathrm{HO}_{3} \mathrm{~S}\left(\mathrm{CH}_{2}\right)_{4} \mathrm{mim}\right] \mathrm{HSO}_{4}$ concentration, microwave-irradiation time, microwave-irradiation power and solid-liquid ratio, were optimized. The highest yield of total flavonol glycosides was

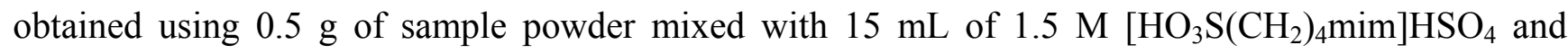
subjecting this to microwave irradiation for $15 \mathrm{~min}$ at a microwave power of $120 \mathrm{~W}$, the yield of total flavonol glycosides was the highest. The proposed ILMASEH approach is an efficient, rapid and simple sample preparation method. 


\section{Acknowledgment}

The authors thank the Special Fund for Forestry Scientific Research in the Public Interest (201204601) for financial support.

\section{References}

1. Kleijnen, J.; Knipschild, P. Ginkgo biloba. Lancet 1992, 340, 1136-1139.

2. Kudolo, G.B.; Dorsey, S.; Blodgett, J. Effect of the ingestion of Ginkgo biloba extract on platelet aggregation and urinary prostanoid excretion in healthy and Type 2 diabetic subjects. Thromb. Res. 2002, 108, 151-160.

3. Guidetti, C.; Paracchini, S.; Lucchini, S.; Cambieri, M.; Marzatico, F. Prevention of neuronal cell damage induced by oxidative stress in vitro: Effect of different Ginkgo biloba extracts. J. Pharm. Pharm. 2001, 53, 387-392.

4. Van Beek, T.A. Ginkgolides and bilobalide: Their physical, chromatographic and spectroscopic properties. Bioorg. Med. Chem. 2005, 13, 5001-5012.

5. Ahlemeyer, B.; Krieglstein, J. Neuroprotective effects of Ginkgo biloba extract. Cell. Mol. Life Sci. 2003, 60, 1779-1792.

6. Van Beek, T.A. Chemical analysis of Ginkgo biloba leaves and extracts. J. Chromatogr. A 2002, 967, 21-55.

7. Lai, S.M.; Chen, I.W.; Tsai, M.J. Preparative isolation of terpene trilactones from Ginkgo biloba leaves. J. Chromatogr. A 2005, 1092, 125-134.

8. Chen, J.X.; Zhang, Y. Rapid microwave-assisted hydrolysis for determination of Ginkgo flavonol glycosides in extracts of Ginkgo biloba leaves. J. Chromatogr. Sci. 2008, 46, 117-121.

9. Zill-e-Huma; Vian, M.A.; Fabiano-Tixier, A.; Elmaataoui, M.; Dangles, O.; Chemat, F. A remarkable influence of microwave extraction: Enhancement of antioxidant activity of extracted onion varieties. Food Chem. 2011, 127, 1472-1480.

10. Acquistucci, R.; Panfili, G.; Marconi, E. Application of the microwave hydrolysis to furosine determination in cereal and dairy foods. J. Agric. Food Chem. 1996, 44, 3855-3857.

11. Panfili, G.; Manzi, P.; Compagnone, D.; Scarciglia, L.; Palleschi, G. Rapid assay of choline in foods using microwave hydrolysis and a choline biosensor. J. Agric. Food Chem. 2000, 48, 3403-3407.

12. Quijano, G.; Couvert, A.; Amrane, A. Ionic liquids: Applications and future trends in bioreactor technology. Bioresour. Technol. 2010, 101, 8923-8930.

13. Welton, T. Room-temperature ionic liquids. Solvents for synthesis and catalysis. Chem. Rev. 1999, 99, 2071-2084.

14. Hoffmann, J.; Nüchter, M.; Ondruschka, B.; Wasserscheid, P. Ionic liquids and their heating behaviour during microwave irradiation-A state of the art report and challenge to assessment. Green Chem. 2003, 5, 296-299.

15. Poole, C.F. Chromatographic and spectroscopic methods for the determination of solvent properties of room temperature ionic liquids. J. Chromatogr. A 2004, 1037, 49-82. 
16. Liu, T.; Sui, X.; Zhang, R.; Yang, L.; Zu, Y.; Zhang, L.; Zhang, Y.; Zhang, Z. Application of ionic liquids based microwave-assisted simultaneous extraction of carnosic acid, rosmarinic acid and essential oil from Rosmarinus officinalis. J. Chromatogr. A 2011, 1218, 8480-8489.

17. Ma, C.; Liu, T.; Yang, L.; Zu, Y.; Chen, X.; Zhang, L.; Zhang, Y.; Zhao, C. Ionic liquid based microwave simultaneous extraction of essential oil and biphenyl cyclooctene lignans from Schisandra chinensis Baill fruits. J. Chromatogr. A 2011, 1218, 8573-8580.

18. Leadbeater, N.E.; Morenius, T.H. A study of the ionic liquid mediated microwave heating of organic solvents. J. Org. Chem. 2002, 67, 3145-3148.

19. Nara, S.J.; Harjani, J.R.; Salunkhe, M.M. Lipase-catalysed transesterification in ionic liquids and organic solvents: A comparative study. Tetrahedron Lett. 2002, 43, 2979-2982.

20. Ma, C.; Liu, T.; Yang, L.; Zu, Y.; Wang, S.; Zhang, R. Study on ionic liquid-based ultrasonic-assisted extraction of biphenyl cyclooctene lignans from the fruit of Schisandra chinensis Baill. Anal. Chim. Acta 2011, 689, 110-116.

21. Yang, L.; Wang, H.; Zu, Y.; Zhao, C.; Zhang, L.; Chen, X.; Zhang, Z. Ultrasound-assisted extraction of the three terpenoid indole alkaloids vindoline, catharanthine and vinblastine from Catharanthus roseus using ionic liquid aqueous solutions. Chem. Eng. J. 2011, 172, 705-712.

22. Yang, L.; Liu, Y.; Zu, Y.; Zhao, C.; Zhang, L.; Chen, X.; Zhang, Z. Optimize the process of ionic liquid-based ultrasonic-assisted extraction of aesculin and aesculetin from Cortex Fraxini by response surface methodology. Chem. Eng. J. 2011, 175, 539-547.

23. Wang, S.; Yang, L.; Zu, Y.; Zhao, C.; Sun, X.; Zhang, L.; Zhang, Z. Design and performance evaluation of ionic liquids-microwave based environmental-friendly extraction technique for camptothecin and 10-hydroxycamptothecin from samara of Camptotheca acuminate. Ind. Eng. Chem. Res. 2011, 50, 13620-13627.

24. Wilkes, J.S. A short history of ionic liquids-From molten salts to neoteric solvents. Green Chem. 2002, 4, 73-80.

25. Chiappe, C.; Leandri, E.; Lucchesi, S.; Pieraccini, D.; Hammock, B.D.; Morisseau, C. Biocatalysis in ionic liquids: The stereoconvergent hydrolysis of trans- $\beta$-methylstyrene oxide catalyzed by soluble epoxide hydrolase. J. Mol. Catal. B Enzym. 2004, 27, 243-248.

26. Mohile, S.S.; Potdar, M.K.; Harjani, J.R.; Nara, S.J.; Salunkhe, M.M. Ionic liquids: Efficient additives for Candida rugosa lipase-catalysed enantioselective hydrolysis of butyl 2-(4-chlorophenoxy) propionate. J. Mol. Catal. B Enzym. 2004, 30, 185-188.

27. Qiao, K.; Yokoyama, C. Koch carbonylation of tertiary alcohols in the presence of acidic ionic liquids. Catal. Commun. 2006, 7, 450-453.

28. Wasserscheid, P.; Sesing, M.; Korth, W. Hydrogensulfate and tetrakis (hydrogensulfato) borate ionic liquids: Synthesis and catalytic application in highly Brønsted-acidic systems for Friedel-Crafts alkylation. Green Chem. 2002, 4, 134-138.

29. Yang, Q.W.; Wei, Z.J.; Xing, H.B.; Ren, Q.L. Brönsted acidic ionic liquids as novel catalysts for the hydrolyzation of soybean isoflavone glycosides. Catal. Commun. 2008, 9, 1307-1311.

30. Chen, Y.; Xie, M.Y.; Gong, X.F. Microwave-assisted extraction used for the isolation of total triterpenoid saponins from Ganoderma atrum. J. Food Eng. 2007, 81, 162-170. 
31. Gray, D.E.; Upton, R.; Chandra, A.; Porter, A.; Harris, R.K. Quantitative analysis of flavonol glycosides in Ginkgo biloba: A comparison of two analytical methods. Phytochem. Anal. 2006, $17,56-62$.

32. Chinese Pharmacopoeia Commission. Pharmacopoeia of the People's Republic of China I; People's Medicinal Publishing House: Beijing, China, 2010; pp. 296-297.

33. European Pharmacopoeia Commission. European Pharmacopoeia, 7th ed.; Council of Europe: Strasbourg, France, 2011; pp. 1828-1829.

34. United States Pharmacopeial Convention. United States Pharmacopeia 32 and National Formulary 27; USP-NF 2009; United States Pharmacopeial Convention: Rockville, ML, USA, 2009; p. 1019.

(C) 2012 by the authors; licensee MDPI, Basel, Switzerland. This article is an open access article distributed under the terms and conditions of the Creative Commons Attribution license (http://creativecommons.org/licenses/by/3.0/). 